Vol. 10, Issue 2, Dec 2020, 1-14

(C) TJPRC Pvt. Ltd.

\title{
EFFECTS ON NASOMAXILLARY COMPLEX OF CLEFT LIP AND CLEFT PALATAL REPAIR AND UNREPAIR
}

\author{
DR. PRADEEP.SUBBAIAH ${ }^{1}$, DR. DHAKSHAINI. M. $\mathbf{R}^{2}$, DR. RAGHUNATH. $\mathbf{N}^{3} \&$ DR. \\ GIRISHKUMARI ${ }^{4}$ \\ ${ }^{1,2,4}$ Department of Orthodontics, JSSAHER, Mysuru, India \\ ${ }^{3}$ Department of Prosthodontics \& Crown and Bridge, JSSAHER, Mysuru, India
}

\begin{abstract}
OBJECTIVE: The cross-sectional analysis was planned to compare complex nasomaxillary growth between operated unilateral cleft lip and palatal repair and unoperated.

MATERIAL AND METHODS

A sample of 36 cleft lip and palate patients (18 unoperated and 18 operated) was selected. Sampling was performed by purposive sampling method. The patients were divided into two groups further divided into three subgroups, and each subgroup consisted of six patients. A statistical test was conducted using the descriptive statistics-independent " $t$ " and ANOVA test

\section{RESULT}

\section{CRANIAL BASE RELATIONSHIPS}

In this study, no significant difference was found in the mean $\mathrm{N}-\mathrm{S}-\mathrm{Ba}$ ( $p=1$ in the birth group to 3 years, $p=0.575$ in the 6 12 age group and 0.786 in the 12-20 age group) and $S-N(p=1$ in the 3-year birth group, $p=1$ in the 6-12 age group and $p=0.106$ in the 12-20 age group) values (Table -1, Figure 1-3) in any of the operated and unoperated cleft group. The results indicated that the cranial base angle and anterior cranial base length did not differ.

\section{MAXILLARY SPATIAL POSITIONING}

The study showed that maxilla is usual in the unoperated category of birth to three years (mean 82.330) and six to twelve years (mean 82.50), whereas it is protrusive (84.60) in the age group of twelve to twenty. The mean value of SNA in an operated group is 76.0 at birth to three years, 77.0 at six to twelve years, and 79.0 at twelve to twenty years, showing that maxilla is retrusive in all three subgroups (Table -2)

\section{CONCLUSION}

The maxilla is normal in an unoperated group till twelve years, whereas maxilla is prognathic in the age group twelve to twenty years. This shows that within the unoperated group there is natural growth potential of the maxilla. In an operated group the maxilla is retrognathic, suggesting that the maxilla growth is affected by surgical repair of the cleft lip and palate.

KEYWORDS: Cleft Lip \&Palate, Nasomaxillary Complex, Operated \& Unoperated
\end{abstract}

Received: May 03, 2020; Accepted: May 23, 2020; Published: Jul 27, 2020; Paper Id.: IJDRDDEC20201 


\section{INTRODUCTION}

Unilateral and bilateral lip and palate clefts are very common human developmental deformities affecting around 1 in 800 1200 patients $^{1}$. Palate clefts occur more commonly in females while lip clefts occur more frequently in males.

Man has a definite idea ofjust what he could look like2. He is liberal enough to allow for certain differences in individuals, but the basic physiognomic pattern is set. A man may have a wrought arm or a club foot, but facial aberrations may be a much greater handicap as the unfortunate person tries to take his place in society. And when this vital attitude to face deformities is coupled with the hypersensitive psychological reaction of the victim, the issue becomes much more complicated.

Attemptsto address the issue of the cleft palate are mostly surgical, and these operations often performed early in life, in some cases just days after birth. For the vast number of cases, before the child begins kindergarten, the surgeon is done with his research and does not have to think about psycho-related and sociological issues caused by incomplete esthetic correction and speech defects. Then the problem becomes the proverbial football, tossed back and forth between the professions of medicine and dentistry, with the speech teacher and psychiatrist occasionally lateral. Several people have thought we need to re-evaluate our performance and failure standards in these cases. What may be a beautiful surgical closure of a cleft palate at two years of age may be a complete psychological and sociological failure at twenty. What may be a nice soft tissue closure of a cleft palate at two years may be a dense unyielding band of fibrous scar tissue at twenty. And what may be a bony closure of a palate at two years may be at least a tenuous bony union at twenty, but also a micro-maxilla and marked facial deformity. The complete answer does not lie in the operation alone. There are some things that come up to haunt us. Why do we see such large variations in the facial appearance within the category of cleft palates? How do we see more severe deformities in adults using an operative technique? Can soft tissue repair tissue prevent growth and development? It is issues like these that prompted the present research, where we tried to distinguish the variations between this congenital deformity and normal trend and the variations in growth between patients with operated and unoperated cleft lip and palate.

The surgical repair of cleft lip or palate or both influence the growth of maxilla and mandible as shown by a study conducted by Omar Gabriel Da Silva et al3 to evaluate influence of lip repair on craniofacial morphology of patients with complete bilateral cleft lip and palate. The study showed a reduction of premaxillary anterior projection and lingual tipping of the upper incisors. This effect on the projection of premaxilla is usually advantageous, except when the increased lip pressure, unfavorable growth pattern, or both retro position the midface profile beyond acceptable sagittal limits.

The present study is an attempt to determine whether there is any difference in maxillary and mandibular growth and the change in relationship of maxilla and mandible to each other and their relative position to the cranial base among operated and unoperated patients by measuring S-N length (length of cranial base), maxillary spatial positioning (SNA, SN-ANS angle, SN-PP angle and Co-A distance), measuring mandibular spatial positioning (SNB, ArGo-Me angle, S-Go-Gn angle, (ANB angle and Wits appraisal), vertical facial height (N-Mc, SN-ANS, SN PNS and S-Go distance). 


\section{MATERIAL AND METHODS}

A total of 36 patients with cleft lip and palate (18 unoperated and 18 operated) have been chosen for the present study. Sampling was performed by purposive method of sampling. The patients were divided into two groups further divided into three subgroups, and each subgroup consisted of six patients.

Group A comprises of unoperated cleft lip and palate patient, which is further divided into 3 subgroups according to age as follows

- Subgroup A1: Birth - 3 years

- Subgroup A2: 6 - 12 years

- Subgroup A3: 12 - 20 years

Group B comprises of operated cleft lip and palate patient which is further divided into 3 subgroups according to age as follows -

- Subgroup B1 - Birth - 3 years

- Subgroup B2 - 6 - 12 years

- Subgroup B3 - 12 - 20 years.

Patient or their respective parents signed the informed consent for the study. The study had been approved by ethics committee, J. S. S. Dental College \& Hospital Mysore Hospital

\section{Materials(Figure 1-7)}

- 8 x 12" TMG, T Mat green-sensitive Kodak Film (Eastman Kodak, Rochester, New York).

- 8 x 12" cassettes with Kodak lamex intensifying screen.

- Cephalostat.

- A well-equipped lightproof dark room.

- Radiographic view box.

- Magnifying lens.

- H pencil.

- Acetate tracing film 36 microns.

- Geometry box.

Sufficient orientation to subjects was given prior to positioning subjects with a sagittal plane at a right angle to the path of the X-ray and the mandible parallel to the floor.

The subjects were trained to keep the jaws in a centric occlusion, and they were advised to keep the same when taking the X-ray in a relaxed position with the lips. Standardized lateral cephalograms were taken with a target film distance of 5 feet; exposure time of $80 \mathrm{Kvp}, 8 \mathrm{ma}$, and 0.7 seconds was used. 
Normal skeletal and dental tissue profile tracing was performed, and the acetate tracing film traced regular lines, planes, angles and linear measurements. (Figure - 8,9) Orientation marks were made over the tracing film to prevent any error while tracing.

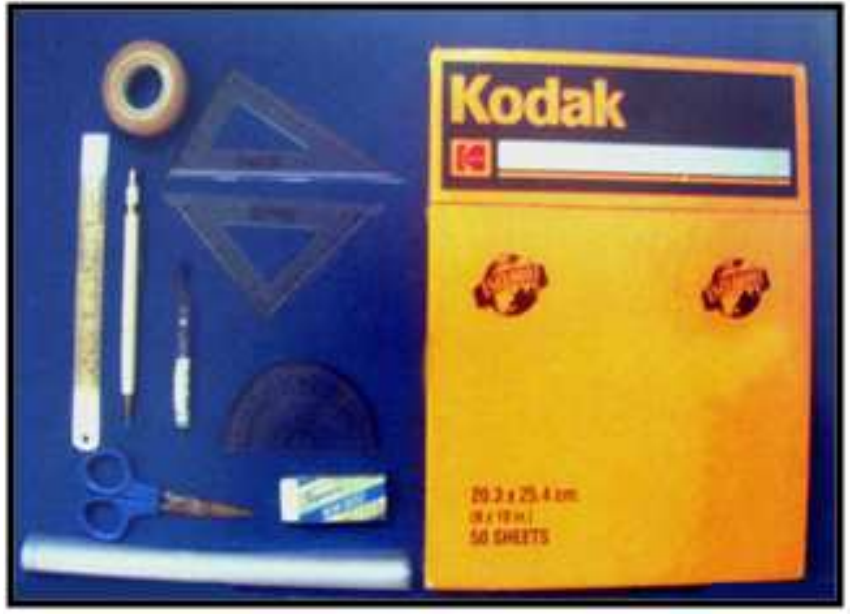

Figure 1: Armamentarium

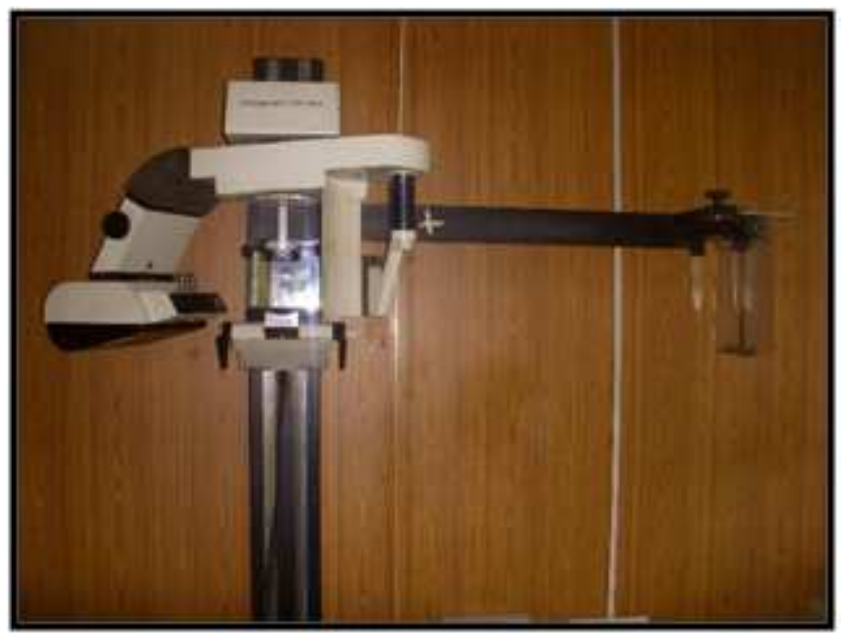

Figure 2: Cephalostat

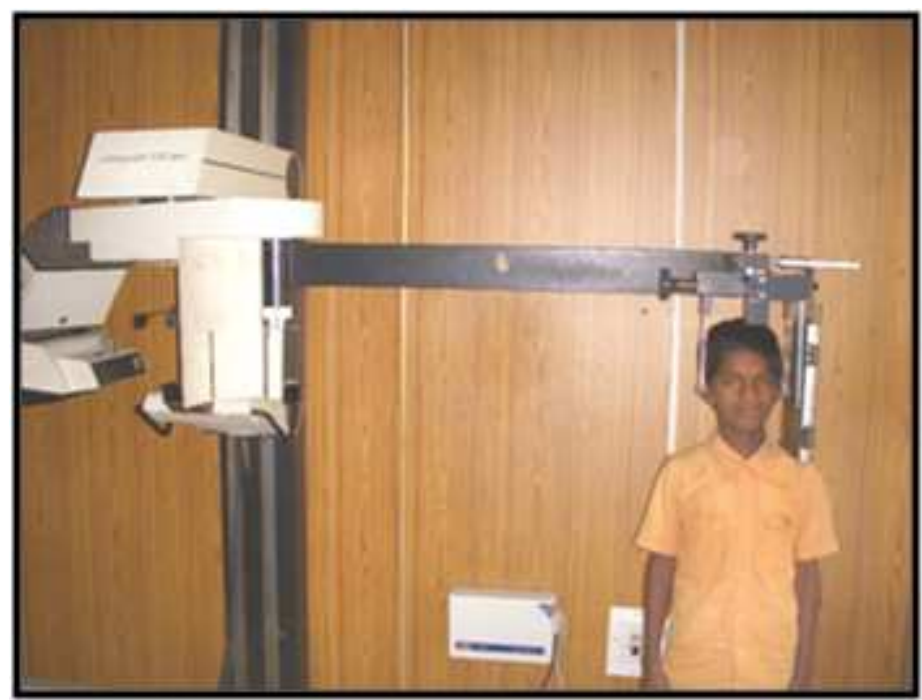

Figure 3: Patient with Cephalostat 


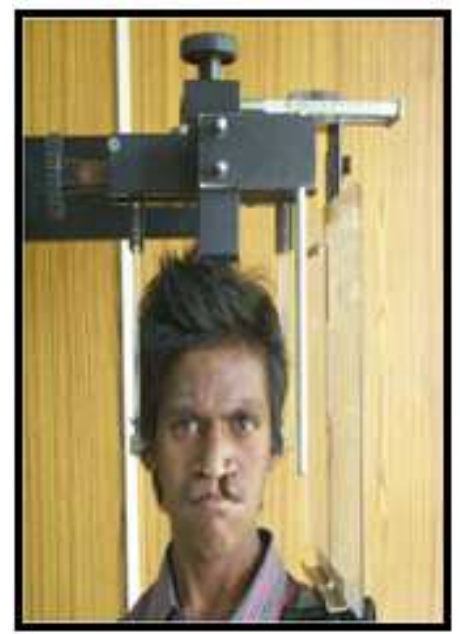

Figure 4: Unoperated cleft lip and palate patient with Cephalostat

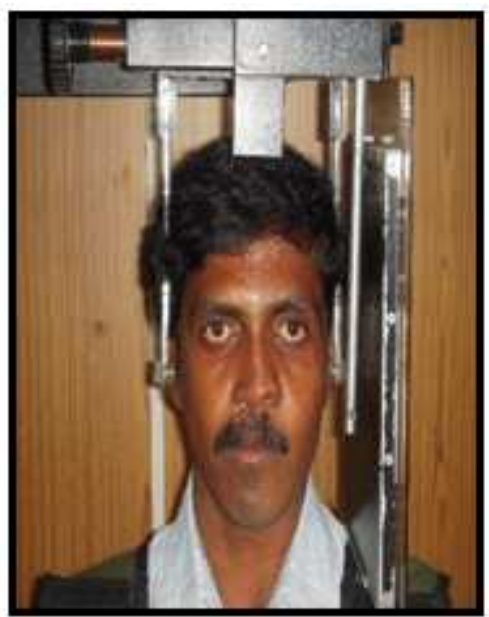

Figure 5: Operated cleft lip and palate patient with Cephalostat

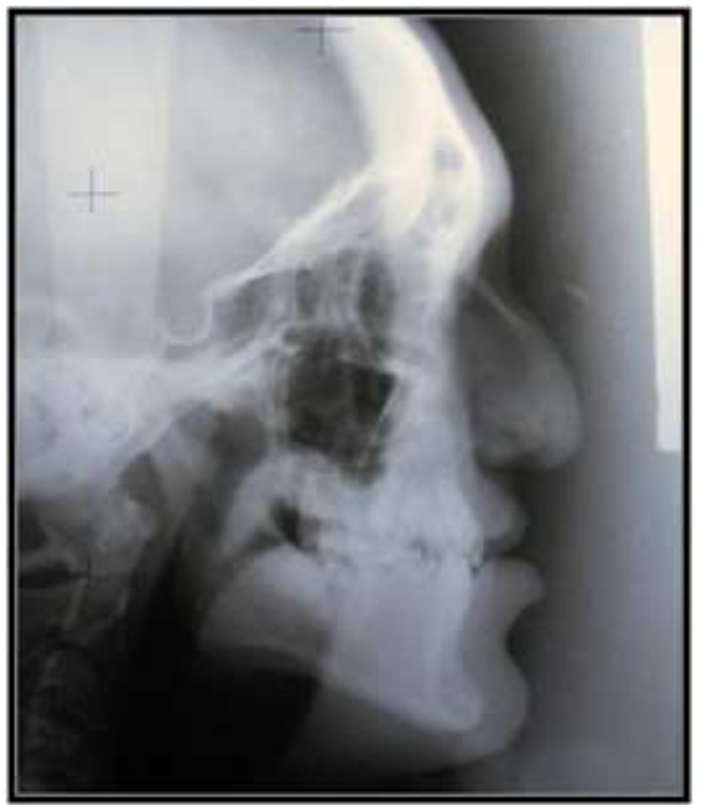

Figure 6: Lateral Cephalometric radiograph of unoperated cleft lip and palate patient 


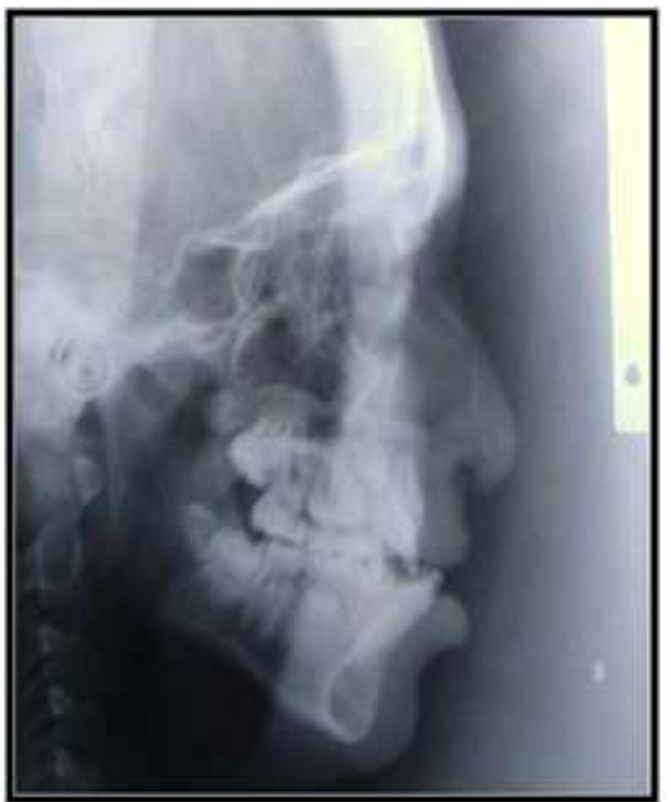

Figure 7: Lateral Cephalometric radiograph of operated cleft lip and palate patient

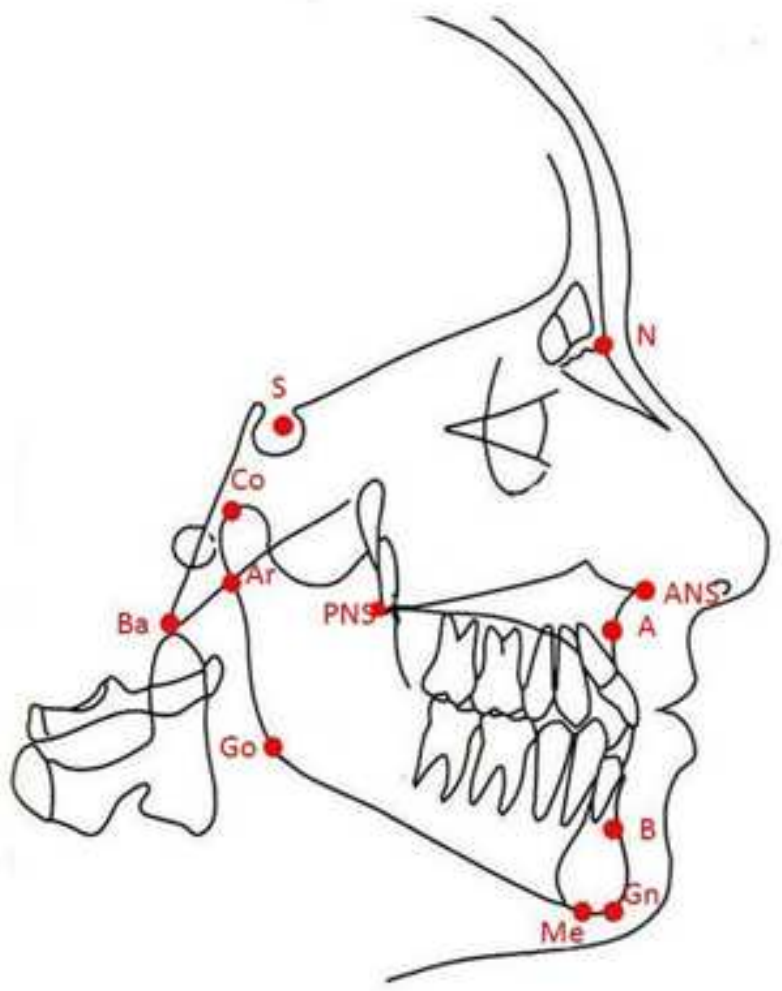

Figure 8: Cephalometric 


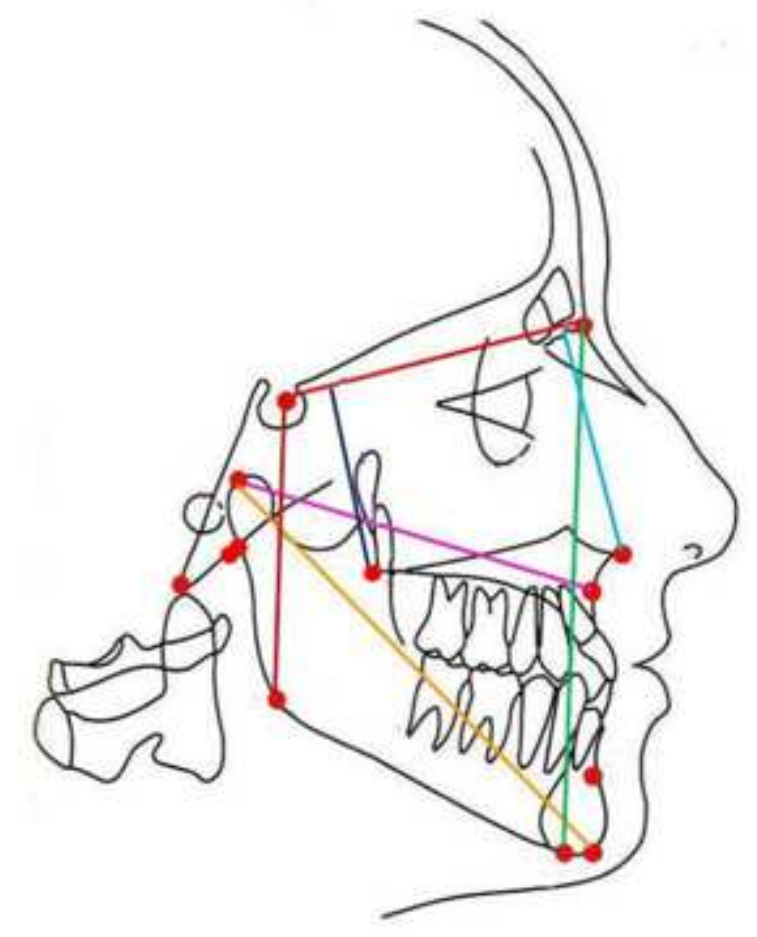

Figure 9: Measurements used in the Study

\section{Methods of Data Collection}

The study was performed based on a standardized lateral cephalogram of patients. The cephalometric measurements were carried out manually and the following variables were evaluated-

1. Angle and length of the cranial base.

Ba-S-N angle and S-N length.

2. Maxillary spatial positioning.

SNA angle, SN-ANS angle, SN-PP angle, Co-A length.

The values of group A were compared with group B of the respective age group to assess any difference in parameters which shows the difference in growth rate among groups $\mathrm{A}$ and $\mathrm{B}$.

Table 1: Means, SD, and t-Test Results for the Cranial Base Cephalometric Measurements

\begin{tabular}{|c|c|c|c|c|c|c|}
\hline \multirow{2}{*}{$\begin{array}{l}\text { Age } \\
\text { Group }\end{array}$} & \multirow{2}{*}{$\begin{array}{l}\text { Cephalometric } \\
\text { Measurement }\end{array}$} & \multicolumn{2}{|c|}{ Unoperated } & \multicolumn{2}{|l|}{ Operated } & \multirow{2}{*}{$\begin{array}{l}\text { t-test } \\
\text { Unoperated Vs } \\
\text { Operated }\end{array}$} \\
\hline & & Mean & SD & Mean & SD & \\
\hline \multirow{2}{*}{ 0-3 years } & BaSN(degrees) & 128.5 & 2.51 & 128.5 & 2.1679 & $1(\mathrm{~ns})$ \\
\hline & SN(millimeters) & 60.6667 & 1.9664 & 60.6667 & 1.7512 & $1(\mathrm{~ns})$ \\
\hline \multirow{2}{*}{ 6-12 years } & BaSN(degrees) & 130.6667 & 1.0328 & 129.8333 & 3.3714 & $0.575(\mathrm{~ns})$ \\
\hline & SN(millimeters) & 67.6667 & 2.5033 & 67.6667 & 1.8619 & $1(\mathrm{~ns})$ \\
\hline
\end{tabular}




\begin{tabular}{|l|l|l|l|l|l|l|}
\hline \multirow{2}{*}{$\begin{array}{l}\text { 12-20 } \\
\text { years }\end{array}$} & Ba-SN(degrees) & 131.166 & 4.2622 & 130.6667 & 1.0328 & $0.786(\mathrm{~ns})$ \\
\cline { 2 - 6 } & SN(millimeters) & 69.8333 & 1.9408 & 71.5 & 1.2247 & $0.106(\mathrm{~ns})$ \\
\hline
\end{tabular}

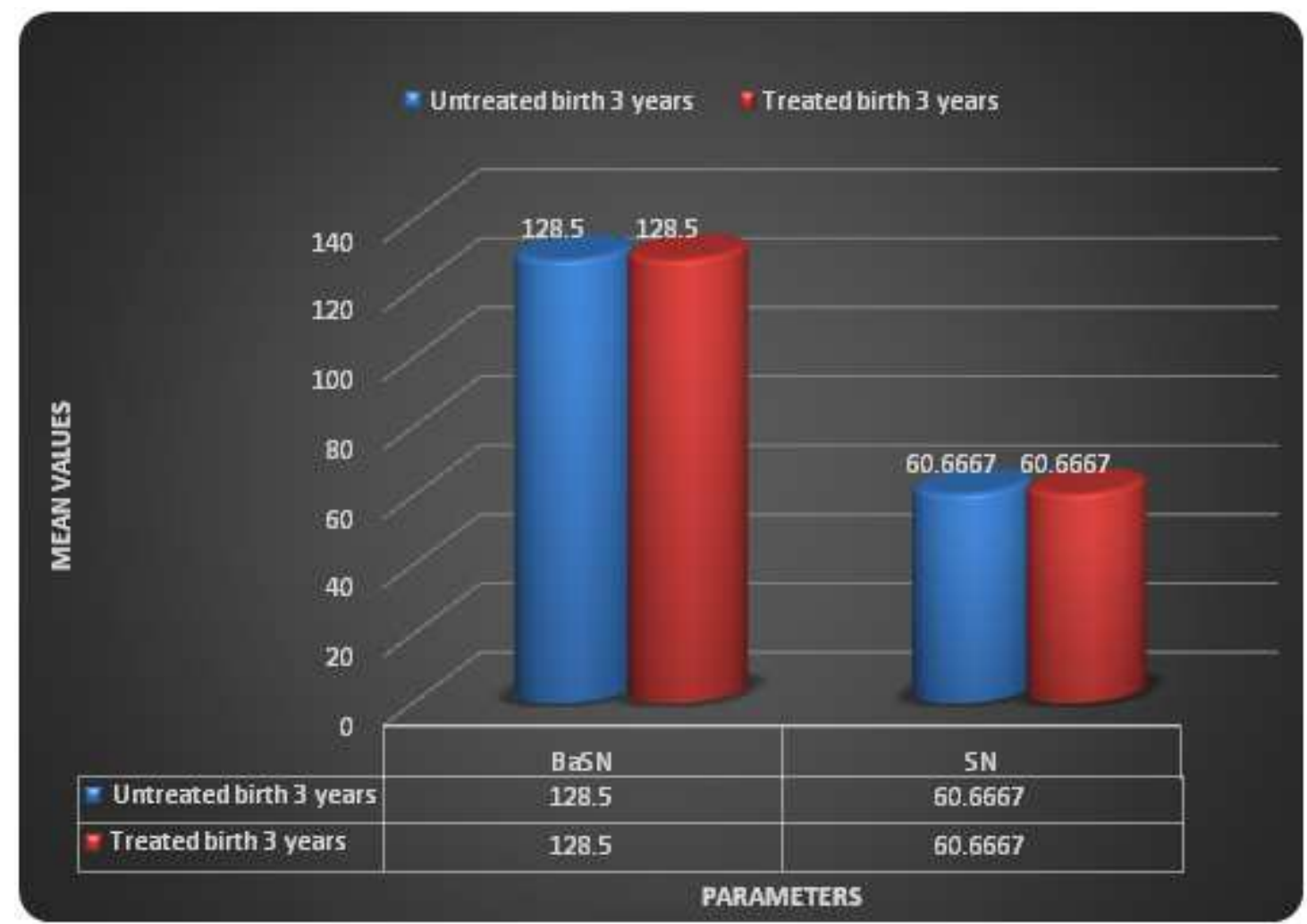

Graph 1: Mean values for cranial base cephalometric measurements in birth to 3 years

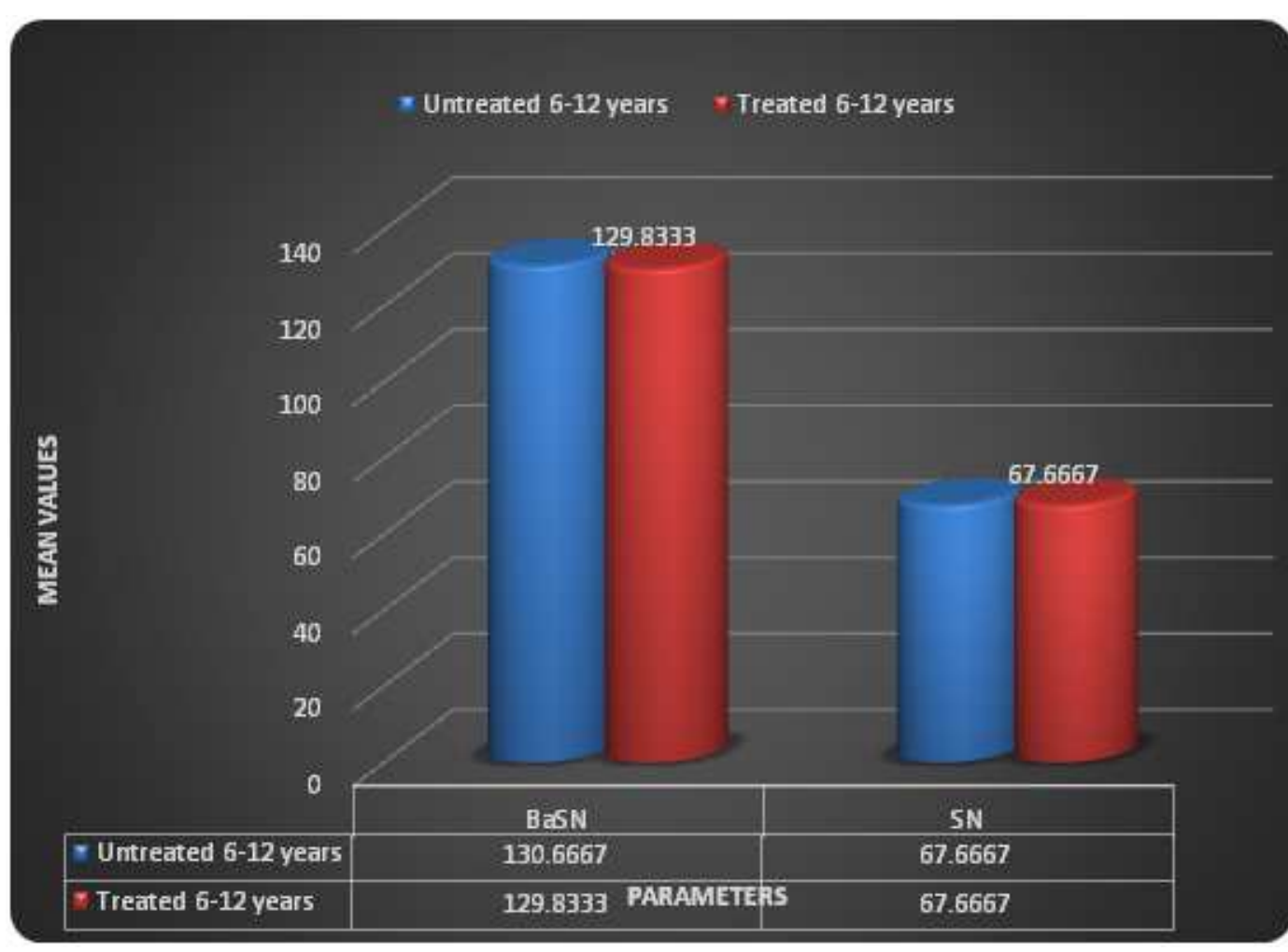

Graph 2: Mean values for cranial base cephalometric measurements in the age group of 6 to 12 years 


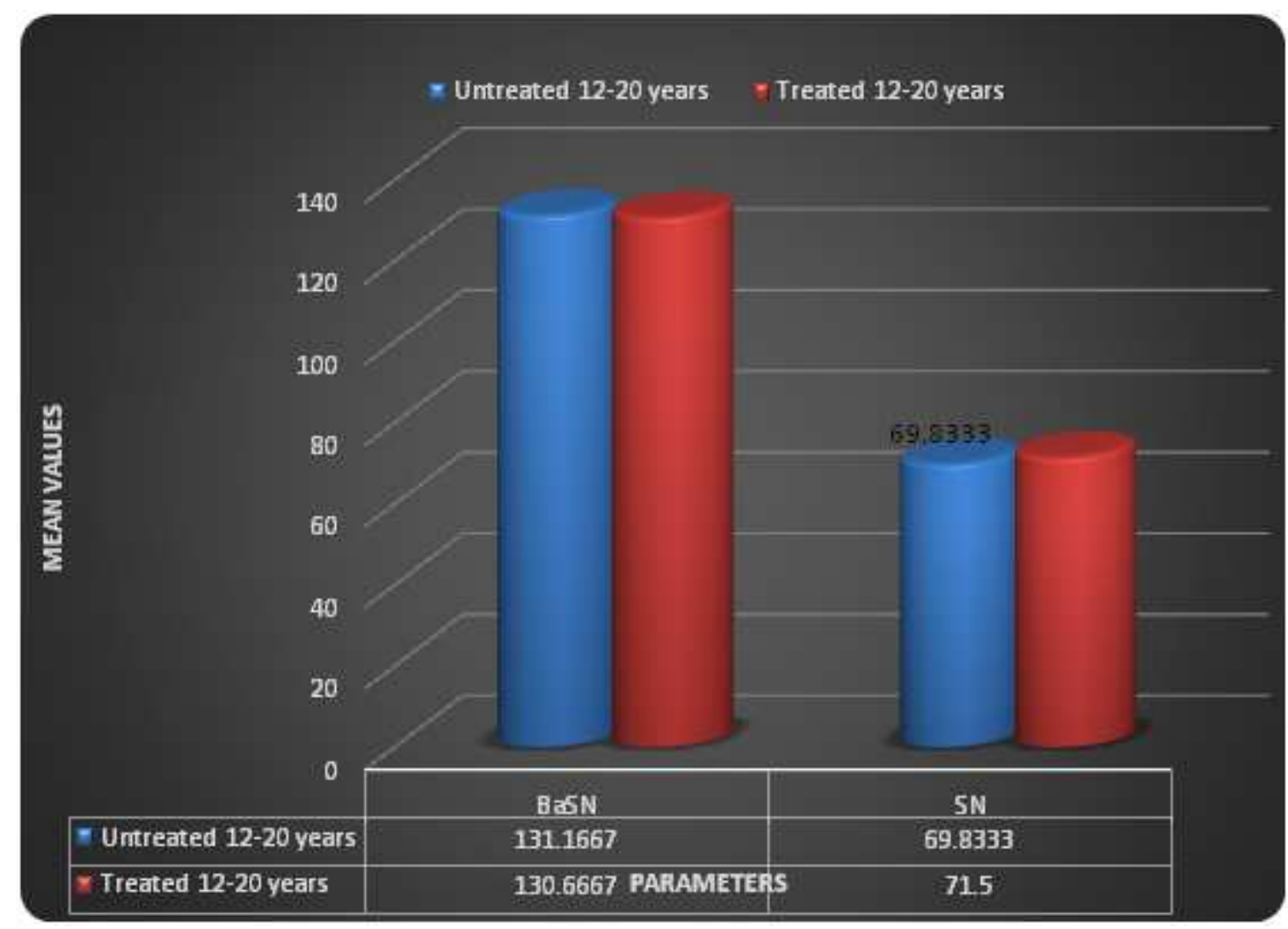

Graph 3: Mean values for cranial base cephalometric measurements in the age group of 12 to 20 years

Table 2: Means, SD, and t-Test Results for the Maxillary Cephalometric Measurements

\begin{tabular}{|c|c|c|c|c|c|c|}
\hline \multirow{2}{*}{$\begin{array}{c}\text { Age } \\
\text { Group }\end{array}$} & \multirow{2}{*}{$\begin{array}{l}\text { Cephalometric } \\
\text { Measurement }\end{array}$} & \multicolumn{2}{|c|}{ Unoperated } & \multicolumn{2}{|c|}{ Operated } & \multirow{2}{*}{$\begin{array}{c}\text { t-test } \\
\text { Unoperated Vs } \\
\text { Operated }\end{array}$} \\
\hline & & Mean & SD & Mean & SD & \\
\hline \multirow{4}{*}{ 0-3 yrs. } & SNA(degrees) & 82.333 & 1.2111 & 74.8333 & 1.1690 & $0.000(\mathrm{~s})$ \\
\hline & SN-ANS(degrees) & 86.8333 & 4.7924 & 85.6667 & 2.0656 & $0.596(\mathrm{~ns})$ \\
\hline & SN-PP(degrees) & 15.3333 & 3.0768 & 14.6667 & 1.7512 & $0.654(\mathrm{~ns})$ \\
\hline & Co-A(millimeters) & 73.333 & 3.3267 & 69.000 & 2.000 & $0.021(\mathrm{~s})$ \\
\hline \multirow{4}{*}{ 6-12 yrs. } & SNA(degrees) & 82.5 & 1.9748 & 74.1667 & 2.1370 & $0.000(\mathrm{~s})$ \\
\hline & SN-ANS(degrees) & 86.333 & 7.0261 & 84.8333 & 5.4559 & $0.789(\mathrm{~ns})$ \\
\hline & SN-PP(degrees) & 8.5 & 3.2711 & 8.6667 & 4.3665 & $0.942(\mathrm{~ns})$ \\
\hline & Co-A(millimeters) & 81.000 & 3.3466 & 68.8333 & 4.5789 & $0.000(\mathrm{~s})$ \\
\hline \multirow{4}{*}{ 12-20 yrs. } & SNA(degrees) & 84.6667 & 5.3166 & 73.1667 & 3.1252 & $0.001(\mathrm{~s})$ \\
\hline & SN-ANS(degrees) & 90.1667 & 5.4191 & 85.6667 & 4.7610 & $0.091(\mathrm{~ns})$ \\
\hline & SN-PP(degrees) & 9.8333 & 3.7103 & 11.5 & 5.5045 & $0.552(\mathrm{~ns})$ \\
\hline & Co-A(millimetres) & 84.1667 & 4.2622 & 67.1667 & 1.7224 & $0.000(\mathrm{~s})$ \\
\hline
\end{tabular}

$\mathrm{s}=$ significant; $\mathrm{ns}=$ non-significant

\section{DISCUSSIONS}

In dental orthopedics, it is essential to have a thorough knowledge of the skeletal and dental components that contribute to malocclusion, as these elements may influence the approach to treatment.

Many key playersfrom dentistry disciplines and other allied sciences have come forward to form a team of professionals working in the treatment of cleft lip / palate patients with surgical and orthodontic treatments. Craniofacial growth of patients with cleft lip / palate was found to differ from that of normal patients 4 and could play a key role in the 
treatment needs and outcomes.

Cephalometry has now been firmly established as the most essential procedure for gaining knowledge of the complexities of the Dentofacial Skeletal Pattern. The description, morphological outlines, measurements and changes in skull growth can be precisely determined using cephalometric radiography.

Surgical and orthodontic interventions have been shown to restore craniofacial growth in patients as demonstrated by studies measuring maxillary and mandibular arch dimensions, intercanine and intermolar width, angle and length of cranial base, growth velocity and dental positioning.

The aim of this study was to determine the difference in maxilla and mandible growth between operated and unoperated patients by measuring and comparing S-N length (cranial base length), TABLE-1 maxillary spatial positioning (SNA, SN-ANS angle, SN-PP angle and Co-A distance) TABLE-2.

\section{CRANIAL BASE RELATIONSHIPS}

In this study, there was no significant difference in the mean $\mathrm{N}-\mathrm{S}-\mathrm{Ba}$ values ( $\mathrm{p}=1$ in the birth to 3 years group, $\mathrm{p}=0.575$ in the 6-12 age group and 0.786 in the 12-20 age group) and $\mathrm{S}-\mathrm{N}$ values ( $\mathrm{p}=1$ in the birth to 3 years group, $\mathrm{p}=1$ in the 6-12 age group and $\mathrm{p}=0.106$ in the 12-20 age group) in any of the operated and unoperated cleft group. The results showed that there was no difference between the cranial base angle and the anterior cranial base length. (Table-1, Graph 1-3)

Our findings were in line with Bishara's results ${ }^{5}$; Krogman ${ }^{6} 1982$ et al, Smahel 1984 ${ }^{7}$, Ross $^{8}$ and but distinct from Bishara et al ${ }^{5}$ whose analysis showed a reduction in cranial base angle.

\section{MAXILLARY SPATIAL POSITIONING}

We also found, following previous reports, that the most striking features of patients with unilateral cleft lip and palate resided in the maxilla. The variations between operated and unoperated patients in the maxilla are as follows:

\section{Angle S-N-A}

A significant difference was found in the mean SNA values of the unoperated group and the group being operated. The study found that maxilla is usual in the unoperated category of birth to three years ( mean 82.330) and six to twelve years (mean 82.50), whereas it is protrusive (84.60) in the age group of twelve to twenty. The mean value of SNA in an operated group is 760 at birth to three years, 770 at six to twelve years, and 790 at twelve to twenty years, showing that maxilla is retrusive in all three subgroups.

This difference in SNA angle is also statistically significant $(\mathrm{p}<0.05)$. TABLE-2 Our results were consistent with the results of Bishara et $\mathrm{al}^{5}$. Bishara et $\mathrm{al}^{9}$ suggested that this finding was due to the protrusive effect of the cleft lip and alveolus, which was neutralized by the vertical and retrusive effect of the cleft palate.

\section{Angle SN-ANS}

The anteroposterior measurement of the maxilla at the level of the palatal plane was similar in all three unoperated and their respective operated group and difference were also statistically insignificant ( $p>0.05)$. Our results were similar to the results of Omar Gabriel Da Silva Filho ${ }^{3}$. This showed that the restraining effect of the anterior maxillary growth due to the lip repair is selective and located within the alveolar bone. The basal part of the premaxilla (SN-ANS) was less influenced by lip repair than its alveolar part (SNA and Co-A both are decreased in the operated group). These (SNA and Co-A) 
decreased cephalometric values mean that the muscular bridge created by surgery can influence the alveolar bone, but it has less influence in the sagittal growth of the premaxillary basal structure (SN-ANS).

\section{SN-PP angle-}

No significant difference $(\mathrm{p}>0.05)$ was found in the palatal plane in respective age groups of both the groups. Both groups exhibited a larger palatal plane angle as compared to normal subjects. This finding is consistent with previous studies of unilateral cleft lip and palate children by Krogman et $\mathrm{al}^{10}$, Smahel $\mathrm{Z}^{7}$.

\section{Co-A length}

A significant difference was found in the mean Co-A (effective maxillary length) values of unoperated and operated cleft lip and palate group. The operated cleft subjects of all the three subgroups had significantly (group A1B1; $\mathrm{p}=0.021$, group $\mathrm{A} 2 \mathrm{~B} 2 ; \mathrm{P} \leq 0.001$ and group $\mathrm{A} 3 \mathrm{~B} 3$; $\mathrm{p} \leq 0.001)$ larger values than that of respective operated subgroups. This decrease in Co-A value was also found by Mars and Houston ${ }^{11}$ and Krogman et $\mathrm{al}^{6}$.

In general, the values showed that the maxilla is near normal in the unoperated cleft lip palate group and retrusive in the operated group. The midfacial hypoplasia observed in the operated group may be the outcome of surgical intervention. In surgically treated patients, inhibition of the normal development of the maxilla has been attributed to scar tissue $^{8}$. There may be no damage to the bone itself because of surgery, but the fibrous scar tissue formed near the bony growth sites may prevent normal maxillary remodeling and development in a downward and forward direction. The extent of interference is directly related to the severity of the cleft because more extensive procedures must be performed to mobilize tissue to close a large defect; resulted in large scar tissue and retarded growth of the maxilla.

\section{CONCLUSIONS}

- There was no significant difference found in the cranial base angle (Ba-S-N) and anterior cranial base length (S$\mathrm{N})$.

- The maxilla is normal till twelve years in an unoperated group whereas in twelve to twenty years age group maxilla is prognathic. It shows that there is a normal growth potential of the maxilla in the unoperated group. In an operated group the maxilla is retrognathic, it indicates that surgical repair of cleft lip and palate affects the growth of the maxilla.

- The anteroposterior length of the maxilla on measuring SN-ANS angle seems to be normal but the angle SNA shows retrognathic maxilla, this proves that the restraining effect of lip repair is selective and located within the alveolar bone. The basal part of premaxilla was less influenced by lip repair than its alveolar part.

\section{SUMMARY}

A sample of 36 subjects with unilateral cleft lip and palate was selected for this study. Out of them, 18 had been operated and the remaining 18 had not been operated. In each group, the subjects were divided into three subgroups according to their age from birth to three years, six to twelve years, and twelve to twenty years.

Various cephalometric points, planes, angles, and linear measurements were used in this study to evaluate the morphology of maxillary, mandible, cranial base, and facial differences.

There was a significant difference between the groups. In the operated group, the maxilla showed reduced growth 
in the anteroposterior plane compared to the unoperated group. No significant difference was found in mandibular morphology. Although the linear dimension and the mandibular plane angle are similar in both groups, the gonial angle was found to increase in the unoperated group, particularly in the 12 to 20 year age group. As a result, maxilla found retruded in the operated group and therefore subjects with cleft lip and palate repaired at an early age group had skeletal class III malocclusion due to retruded maxilla.

This demonstrated the restraining effect of the scar tissue formed as a result of a surgical procedure for the early closure of the cleft lip and palate.

The study's attempt will give an idea of craniofacial morphology and the difference in growth between operated and untreated subjects. It also helps us understand the effect of surgery on lip and palate closure. This will help us to get to the right diagnosis and treatment planning.

\section{ACKNOWLEDGMENT}

I would like to acknowledge Ethics Committee, J. S. S. Dental College and Mysuru Hospital for providing clearance for the study to be conducted. And I would also like to acknowledge the support of my teachers and co-staff at all stages. Conflict of interest - No Conflict

Funding Source - no source of Financial support.

\section{REFERENCES}

1. William G. Shafer, Maynard K. Hine, Barnet M. Levy, Charles E. Tounich - A textbook of oral pathology, $4^{\text {th }}$ Edition

2. Touro M. Graber. Cephalometric analysis of the development pattern and facial morphology in cleft palate. Angle Orthodontist, April 1949; 19 (2): 91 -98.

3. Omar Gabriel Da Silva Filho, Jose Valladares Neto, Leopoldino Capelozza Filho, Jose Alberto De Souza Freitas.Influence of lip repair on craniofacial morphology of patients with complete bilateral cleft lip and palate. Cleft palate - Craniofacial journal, March 2003; 40(2):144 - 153.

4. Claudia Zuniga, Rodolfo Mirallesa, Raul Carvajal, Maria Jose Ravera, Paula Contreras and Gabriel Cavada. Comparative study between children with and without cleft lip and cleft palate. Cleft palate- Craniofacial journal, May 2000; 37(3): 281 285.

5. Samir E. Bishara. Cephalometric evaluation of facial growth in operated and unoperated individuals with isolated clefts of the palate. Cleft palate journal, July 1973; 10 (3): 239 - 246.

6. Wilton M. Krogman, Ram B. Jain, Ross E. Long. Sex differences in craniofacial growth from one month to ten years in cleft lip and palate. Cleft Palate Journal, January 1982; 19(1): 62-71.

7. Samuel Z. Craniofacial morphology in adults with bilateral complete cleft lip and palate. Cleft Palate Journal, July 1984; 21(3): $159-232$.

8. R.Bnce Ross. Treatment variables affecting facial growth in complete unilateral cleft lip and palate. Pant 1: treatment affecting growth. Cleft palate journal, January 1987; 24(15): 5 - 23 .

9. Samir E.Bishara, Roberto Sosa Martinez de Arrendondo, Herran Patron Vales. Dentofacial relationships in persons with unoperated clefts: Comparisons between three cleft types. American Journal of Orthodontics and Dentofacial Orthopaedics, June 1985; 87 (6): $481-505$. 
10. Wilton M. Krogman, M. Mazaheri, R. L. Harding, K. Isiguro, G. Bariana, J. Meier, H. Canter, Paul Ross. A longitudinal study of the craniofacial growth pattern in children with clefts as compared to normal, birth to six years. Cleft palate journal, January 1975; 12 (1): $59-84$.

11. Michal Mars and William J.B. Houston. A preliminary study of facial growth and morphology in unoperated male unilateral cleft lip and palate subjects over 13 years of age. Cleft palate-Craniofacial Journal; January 1990, 27(1):7-10. 
